\title{
EDITORIAL
}

\section{Índice Bibliográfico Nacional - IBN Publindex 2004 - 2010 National Bibliographic Index - IBN Publindex 2004 - 2010}

El Sistema Nacional de Indexación de Publicaciones especializadas de Ciencia, Tecnología e Innovación en Colombia, ha cumplido con el compromiso de reconocer y clasificar en cuatro categorías, las revistas científicas colombianas que cumplen con ciertos niveles de calidad. Esta labor se ha desarrollado a través del Índice Bibliográfico Nacional Publindex, IBN Publindex. Con este instrumento, además de capturar la información particular de cada revista, organizarla, estructurarla y dejarla disponible para la comunidad científica, también ha contribuido con la visibilidad tanto nacional como internacional de las publicaciones colombianas (1).

El IBN Publindex, a través de las directrices de sus directivos, propende para que los editores colombianos presenten sus revistas y sean sometidas a su clasificación mediante convocatorias anuales, previo cumplimiento de requisitos mínimos. Por otra parte, se puede observar que los editores, dentro de sus políticas de mejoramiento integral de sus revistas, también optan por presentarlas al mayor número de directorios, índices bibliográficos y bases de datos internacionales, cumpliendo muchas de ellas con altos estándares de exigencia, con lo cual se incrementa sustancialmente el reconocimiento y visibilidad de las mismas (2).

Es innegable el efecto que el IBN Publindex ha ejercido en la comunidad científica y académica colombiana, si solo se compara que en la primera actualización del año 2004, independientemente de las categorías, dicho índice denunció la existencia de 91 revistas y en la primera actualización de 2010 existen 368 revistas. Estos guarismos en términos simples, significan la aparición de nuevas revistas año tras año, lo que se ve reflejado en un incremento superior al 400\% en el periodo 2004-2010 (Tabla1).

Tabla 1. Actualizaciones Índice Bibliográfico Nacional - Publindex - 2004 -2010.

ACTUALIZACIONES DE PUNBLINDEX - COLOMBIA

\begin{tabular}{ccccccccccccc} 
REVISTAS & 2004 & 2004 & 2005 & 2005 & 2006 & 2006 & 2007 & 2007 & 2008 & 2008 & 2010 \\
& $1 . a$ & $2 . a$ & $1 . a$ & $2 . a$ & $1 . a$ & $2 . a$ & $1 . a$ & $2 . a$ & $1 . a$ & $2 . a$ & $1 . a$ \\
\hline A1 & 1 & 1 & 2 & 2 & 2 & 3 & 4 & 5 & 9 & 15 & 23 \\
A2 & 9 & 9 & 5 & 5 & 9 & 15 & 22 & 31 & 41 & 38 & 66 \\
B & 7 & 11 & 32 & 38 & 43 & 46 & 46 & 49 & 52 & 68 & 69 \\
C & 74 & 98 & 89 & 111 & 130 & 138 & 140 & 136 & 142 & 141 & 210 \\
\hline Total & 91 & 119 & 128 & 156 & 184 & 202 & 212 & 221 & 244 & 262 & 368 \\
\hline
\end{tabular}

Por supuesto, es imprescindible mencionar como complemento importante el compromiso que instituciones y editores han asumido frente a este reto que beneficia a toda la comunidad académica y científica de Colombia.

Ahora bien, al considerar el incremento de revistas por categorías en términos de porcentaje, sorprende que para las revistas clasificadas en categoría $A 1$, dicho incremento fuera del $2300 \%$, para la categoría A2 de $733 \%$, para la categoría B de $986 \%$ y para la categoría C del $284 \%$, observándose un incremento constante a través de los años (Figura 1 ).

Si bien la tarea de mejoramiento de las revistas nunca termina, también es cierto que la comunidad académica y científica de Colombia tiene que creer en lo nuestro, en nuestras revistas, debemos consultarlas en los recintos universitarios, institutos de investigación, sociedades y fundaciones entre otros, e ir creando la cultura de las citaciones de lo nuestro, repetimos, de nuestras revistas, de nuestra ciencia, en definitiva de nuestro nuevo conocimiento. 


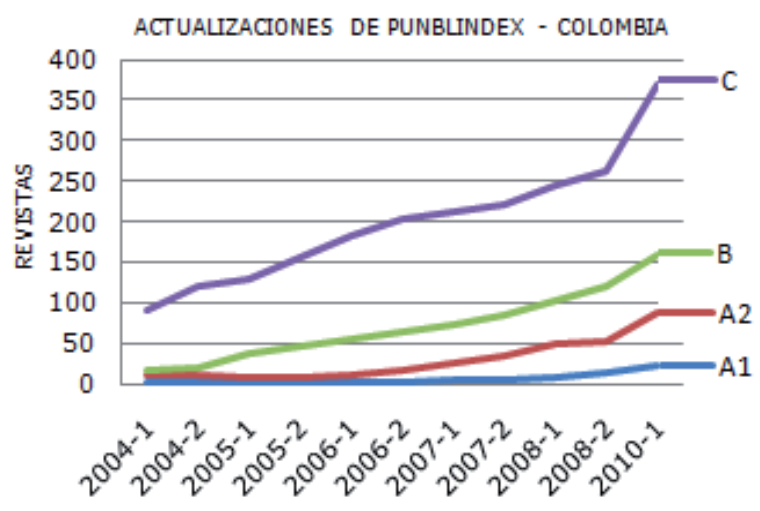

Figura 1. Incremento del número de revistas colombianas a través de los años periodo 2004-2010.
Como lo comentáramos en un editorial hace algún tiempo (3), insistimos en que Colciencias debería diseñar una política de estímulos para aquellas revistas que logren alcanzar la máxima categoría de Publindex. Por otra parte, pero conexa, creemos que una manera de estimular la participación de los investigadores como pares evaluadores de artículos científicos, sería que aquellos que sean integrantes de grupos de investigación clasificados en Colciencias, les sea asignado una puntación de acuerdo con la categoría del grupo al cual pertenece y, para el caso de pares evaluadores de las universidades públicas colombianas, ¿̇por qué no reconocerles algún punto dentro del decreto 1279 de junio 19

de 2002 ? o en su defecto, puntos no constitutivos de salario.

La mayoría de las revistas tienen en común el problema de su financiación constante, así como el tema de los pares evaluadores; estos son escasos, se toman su tiempo para responder y es lógico que estén ocupados adelantando proyectos de investigación, desarrollando actividades de docencia directa o en funciones administrativas de la institución a la cual pertenecen. En el nuevo ámbito de calidad de la educación colombiana pregonado por el actual gobierno, el Ministerio de Educación Nacional, por ejemplo, podría aportar recursos adicionales a aquellas universidades que tengan revistas indexadas en Publindex, acorde con su categoría de clasificación ( 1 1, A2, B y C). Tampoco debemos olvidar que sobre el sistema de educación superior de Colombia prácticamente recae el $90 \%$ de la investigación e innovación tecnológica en las diferentes áreas del saber, especialmente sobre la universidad pública. La empresa privada o el sector productivo aun no realizan o no pueden hacer investigación para solucionar sus propios problemas y la universidad siempre ha estado presta a colaborar y ha contribuido a resolverlos. Las revistas científicas en este caso, son la "radio escrita" encargada de informar a la sociedad que las contribuciones de sus ciudadanos les han sido devueltas con creces. En la actualidad Colombia aporta solo el $2 \%$ de la producción científica iberoamericana (4), pero suponemos que esos aportes antes de la "era Publindex", fueron mucho menores.

En ese sentido, "la explosión" de revistas en Colombia bajo criterios de calidad, es sin duda un avance grandioso para la academia, la visibilidad del país y para los investigadores. No obstante, se corre el peligro de fracasar estrepitosamente si la nación a través de Colciencias y el Ministerio de Educación Nacional no estimulan el mismo escalafón que han creado.

Marco González T. M.Sc.

Salim Mattar V. Ph.D.

\section{REFERENCIAS}

1. Colciencias. Sistema Nacional de Indexación y Homologación de Revistas Especializadas de CT+I. [En Linea]. [Fecha ingreso 24/12/2010]. URL disponible en: http://201.234.78.173:8084/ publindex/jsp/content/bbnp.jsp.

2. Colciencias. Índice Bibliográfico Nacional - IBN Publindex I Actualización 2010. [En Linea]. [Fecha ingreso 24/12/2010]. URL disponible en: http://201.234.78.173:8084/publindex/ EnIbnPublindex/resultados.do.

3. González M, Mattar S. Impacto de las revistas científicas en los indicadores de la universidad pública (Editorial). Rev MVZ Córdoba 14(1):1529-1530, 2009.

4. Fayad R. Anotaciones para una reflexión sobre la educación superior en Colombia. Rev Fac Med 2010; 18:123-133. 